\title{
Risk assessment and predicting outcomes in patients with depressive symptoms: a review of potential role of peripheral blood based biomarkers
}

\author{
Bhautesh D. Jani ${ }^{1}$, Gary McLean ${ }^{1}$, Barbara I. Nicholl' ${ }^{1}$ Sarah J. E. Barry ${ }^{2}$, Naveed Sattar $^{3}$, \\ Frances S. Mair ${ }^{1}$ and Jonathan Cavanagh ${ }^{4 *}$
}

${ }^{1}$ General Practice and Primary Care, Institute of Health and Wellbeing, College of Medical, Veterinary and Life Sciences, University of Glasgow, Glasgow, UK

${ }^{2}$ Robertson Centre for Biostatistics, Institute of Health and Well Being, College of Medical, Veterinary and Life Sciences, University of Glasgow, Glasgow, UK

${ }^{3}$ BHF Glasgow Cardiovascular Research Centre, Institute of Cardiovascular and Medical Sciences, College of Medical, Veterinary and Life Sciences, University of Glasgow, Glasgow, UK

${ }^{4}$ Mental Health and Wellbeing, Institute of Health and Wellbeing, College of Medical, Veterinary and Life Sciences, University of Glasgow, Glasgow, UK

\section{Edited by:}

Ganesan Venkatasubramanian,

National Institute of Mental Health

and Neuro Sciences, India

Reviewed by:

Muralidharan Kesavan, National

Institute of Mental Health and

Neuro Sciences, India

Monojit Debnath, National Institute

of Mental Health and Neuro

Sciences, India

*Correspondence:

Jonathan Cavanagh, R127 Level 1, Mental Health and Wellbeing,

Sackler Institute, University of

Glasgow, Neurology Block, Southern

General Hospital, Glasgow G51

4TF, UK

e-mail: jonathan.cavanagh@

glasgow.ac.uk
Depression is one of the major global health challenges and a leading contributor of health related disability and costs. Depression is a heterogeneous disorder and current methods for assessing its severity in clinical practice rely on symptom count, however this approach is unreliable and inconsistent. The clinical evaluation of depressive symptoms is particularly challenging in primary care, where the majority of patients with depression are managed, due to the presence of co-morbidities. Current methods for risk assessment of depression do not accurately predict treatment response or clinical outcomes. Several biological pathways have been implicated in the pathophysiology of depression; however, accurate and predictive biomarkers remain elusive. We conducted a systematic review of the published evidence supporting the use of peripheral biomarkers to predict outcomes in depression, using Medline and Embase. Peripheral biomarkers in depression were found to be statistically significant predictors of mental health outcomes such as treatment response, poor outcome and symptom remission; and physical health outcomes such as increased incidence of cardiovascular events and deaths, and all-cause mortality. However, the available evidence has multiple methodological limitations which must be overcome to make any real clinical progress. Despite extensive research on the relationship of depression with peripheral biomarkers, its translational application in practice remains uncertain. In future, peripheral biomarkers identified with novel techniques and combining multiple biomarkers may have a potential role in depression risk assessment but further research is needed in this area.

\section{Keywords: peripheral biomarkers, depression, treatment response, risk assessment, outcomes}

\section{INTRODUCTION}

\section{HETEROGENEITY IN DEPRESSIVE SYMPTOMS}

Depression is a heterogeneous disorder with a spectrum ranging from minor/sub threshold to major depressive disorder (MDD) (Rodriguez et al., 2012). According to the latest global disease burden study, depressive disorders (MDD and sub threshold/minor depression) are the leading cause of disability and disease burden globally (Ferrari et al., 2013). The methods currently available for risk assessment and stratification of symptom severity for patients presenting with depressive symptoms rely predominantly on counting the absolute number of depressive symptoms present but there is no universally accepted standardized definition. The Diagnostics and Statistical Manual (DSM)-IV's diagnosis of a MDD requires the presence of at least 5 out of 9 symptoms of depression with significant impairment or distress, while those presenting with at least 2 but less than 5 symptoms and no previous history of MDD are stratified as sub threshold or minor depression (American Psychiatric Association, 2000). The category of sub threshold depression has been removed from recently published DSM-V (American Psychiatric Association, 2013). On the other hand, the International Classification of Diseases (ICD-10) stratifies depressive symptoms on the basis of the number of depressive symptoms present into mild (4 out of 10), moderate ( 5 or 6 out of 10) and severe (7 or more out of 10) depressive episode (WHO, 2010). However, this approach has been questioned owing to lack of consensus (Wittchen et al., 2001; Hegerl et al., 2012) and because it ignores the complexity and diversity of depressive symptoms (Goldberg, 2011). The bulk of patients reporting with depressive symptoms are managed in primary care; however the rate of accurate stratification of depressive symptoms in primary care was less than $50 \%$ based on a meta-analysis involving more than 50,000 patients (Mitchell et al., 2009). Minor or sub threshold depression has been associated with severe deficits in psychological well-being and quality of life, progression to major disorder and increased mortality (Cuijpers and Smit, 2002; Lyness et al., 2006; Nierenberg et al., 2010), 
underlining the need for its early identification and appropriate treatment.

\section{MANAGEMENT OF DEPRESSION}

The uncertainty in stratifying depression severity based on symptom count affects subsequent management. A review of treatment guidelines for depression across North America and Europe revealed that "mild MDD and sub threshold depression has the most variance in recommendations"; with suggested approaches ranging from watchful waiting to active treatment with antidepressants (Davidson, 2010). In the last decade, three separate meta-analyses reported that the efficacy of antidepressants is related to the initial severity of depression and they may not be effective in the treatment of mild depression (Khan et al., 2002; Kirsch et al., 2008; Fournier et al., 2010). However, this view has been challenged recently with emerging evidence suggesting that the efficacy of antidepressants in depression may not be related to its initial severity (Gibbons et al., 2012; Fountoulakis et al., 2013). Psychological therapies have been found to be effective in the management of mild depression but they have not been subjected to the same level of scrutiny as pharmacological therapies as yet (Cuijpers et al., 2007). The ambiguity surrounding stratifying the severity of depression based on symptom count and its subsequent management could partially explain why most patients with depression do not receive adequate treatment and many treated patients develop treatment resistance and relapse (Thase, 2006; Nemeroff, 2007). Therefore, different approaches for risk assessment and severity stratification of patients presenting with depressive symptoms are urgently required.

\section{PATHOGENESIS OF DEPRESSION}

The etiopathogenesis of depression has been extensively studied over the last five decades with various explanatory mechanisms involving different physiological systems, suggesting heterogeneity (Zunszain et al., 2011). The "monoamine hypothesis of depression" was proposed in the 1960s with early work showing increased levels of plasma tryptophan (serotonin precursor) in patients with major depression (Coppen et al., 1973). Failure to suppress cortisol in response to dexamethasone in patients with depression was the initial finding which supported the role of hypothalamic-pituitary-adrenal (HPA) axis hyperactivity in the pathophysiology of depression (Carroll et al., 1981). The "cytokine hypothesis" suggests that depression is triggered, in part, via inflammatory processes in response to various internal and external stressors, following some seminal work in the early 1990s (Maes et al., 1991). This hypothesis has been further developed to suggest that inflammatory, oxidative and nitrosative stress are causally related to depression and increased translocation of lipopolysaccharide from gram negative bacteria may aggravate these pathways (Maes, 2008). The "neurogenesis hypothesis" of depression proposes that depression is characterized by neurodegeneration and impaired neurogenesis in the brain, in particular the hippocampus region (Sapolsky, 2004). The bi-directional relationship between metabolic syndrome and depression and their common pathophysiological pathways has been reported extensively (McIntyre et al., 2009; Vancampfort et al., 2013). Of course, several hypotheses may overlap or be relevant here.

\section{BIOMARKERS OF DEPRESSION}

A biomarker can be defined as a characteristic that is objectively measured and evaluated as an indicator of normal biologic processes, pathogenic processes, or pharmacologic responses to a therapeutic intervention (Biomarkers Definitions Working Group, 2001). The research into pathogenesis of depression has led to a strong evidence base supporting a cross-sectional relationship between depressive symptoms and a number of different biomarkers pertaining to some of the physiological systems described above, but their role, if any, in predicting clinical outcomes in depression remains unclear (Macaluso et al., 2012). Peripheral biomarkers (blood based) are relatively non-invasive (other than the need for a blood sample) and easier to measure; hence they have a greater potential for translational application into routine clinical practice, when compared to imaging, genetic and CNS biomarkers. Peripheral biomarkers such as those related to HPA axis, inflammatory and monoamine systems may have a role in the diagnosis of depression by identifying a "biological sub-type" of depression, and in prognostication of depression by predicting treatment response, which in turn could help in its severity stratification and management (Fisar and Raboch, 2008; Leuchter et al., 2010; Schmidt et al., 2011). Various inflammatory and oxidative stress biomarkers have been proposed to have a potential role, not only in predicting antidepressant response, but also in enhancing treatment matching and onset prediction in patients with depression (Lopresti et al., 2014). For example, in a study based on a multi-center trial involving depression patients, showed an interaction between antidepressants and C-reactive protein with patients with raised CRP more likely to respond to nortripytline than escitalopram (Uher et al., 2014).

\section{AIMS OF THE REVIEW}

To attempt to address this issue, we examine the evidence base exploring the potential role of peripheral biomarkers at baseline in predicting future outcomes in patients with depression. We discuss the potential role of peripheral biomarkers identified using novel and emerging techniques such as proteomics, metabolomics, genetics, and epigenetics in risk assessment and outcome prediction in patients with depressive symptoms. We also review the relationship between depressive symptoms and a composite index score derived using multiple peripheral biomarkers such as allostatic index (AI) and discuss its possible role in future, in management of depression.

\section{METHODS}

Two electronic databases (Ovid Medline and Embase) were searched for studies published between 1946 and Jan 2013 using the MESH terms "Biological markers" AND "Depression." All original and review studies using peripheral biomarkers at baseline as a risk assessment tool for predicting future outcomes in patients with depression were included. Clinical outcomes pertaining to both mental health (e.g., depressive symptoms) and physical health (e.g., cardiovascular event) were included. Only studies published in English language were considered for inclusion. Studies related to animal, imaging biomarkers, cerebrospinal fluid biomarkers, and mood disorders other than depression were excluded. Studies which investigated the role of 
depressive symptoms and peripheral biomarkers independently in predicting adverse physical outcomes but did not examine the interaction between depressive symptoms and peripheral biomarkers, or in other words did not perform a sub-group analysis in patients with depression, were excluded. Studies that investigated changes in peripheral biomarker levels following treatment for depression and which didn't report any correlation between baseline biomarker levels and depressive symptoms were excluded as the aim of this review was to focus on the use of peripheral biomarkers at baseline or pre-treatment as a predictive tool of clinical outcome (both mental and physical), rather than a change in biomarker level itself. The search strategy returned 1096 studies from two databases after excluding duplicates (see Figure 1 for details).

Title, abstract and full text screening followed by reference and citation searching and data extraction were carried out independently by two researchers (Bhautesh D. Jani and Gary McLean). The data extraction comprised of study sample size and country, type of study and setting, details of how depression was diagnosed and treated, follow-up duration, biomarkers assessed, clinical outcomes studied and potential bias in the results. The description of methodology used by included studies for biomarker measurement and the source of peripheral biomarker (i.e., serum or plasma or whole blood) was also reviewed in data extraction.

\section{RESULTS}

\section{INCLUDED STUDIES AND THEIR CHARACTERISTICS}

There was extensive evidence (109 studies) exploring and supporting the cross-sectional relationship between depression and different peripheral biomarkers. However, only a minority of studies ( $n=14$ ) explored the use of peripheral biomarkers to predict outcomes in patients with depression. Fifteen papers were included for data extraction; which consisted of nine prospective cohort studies (Duval et al., 1996; Perez et al., 1998; Alvarez et al., 1999; Johnston et al., 1999; Lanquillon et al., 2000; Ladwig et al., 2005; Binder et al., 2009; Jokinen and Nordstrom, 2009; Baune et al., 2012), three case-control studies (Arolt et al., 2003; Baldwin et al., 2006; Jang et al., 2008), two randomized controlled trials (Kin et al., 1997; Raison et al., 2013) and one meta-analysis (Ribeiro et al., 1993). Full details of included studies are summarized in Table 1.

Sample sizes ranged from 8 to 986 with sample sizes of less than 50 participants in00206 studies (Duval et al., 1996; Alvarez et al., 1999; Johnston et al., 1999; Lanquillon et al., 2000; Arolt et al., 2003; Baldwin et al., 2006), while three studies had a sample size of 25 or less (Alvarez et al., 1999; Lanquillon et al., 2000; Arolt et al., 2003). Follow-up duration ranged from 4 weeks to 18 years with the follow-up duration being less than 6 months in 9 studies(Duval et al., 1996; Kin et al., 1997; Perez et al., 1998; Alvarez et al., 1999; Lanquillon et al., 2000; Arolt et al., 2003; Jang et al., 2008; Binder et al., 2009; Raison et al., 2013) while only 5 studies followed their subjects for more than 12 months (Johnston et al., 1999; Ladwig et al., 2005; Baldwin et al., 2006; Jokinen and Nordstrom, 2009; Baune et al., 2012). Six studies used a diagnostic interview technique (Duval et al., 1996; Johnston et al., 1999; Lanquillon et al., 2000; Arolt et al., 2003; Baldwin et al., 2006; Jang et al., 2008) and seven studies used a depression rating scale (Kin et al., 1997; Perez et al., 1998; Alvarez et al., 1999; Ladwig et al., 2005; Binder et al., 2009; Baune et al., 2012; Raison et al., 2013) while diagnostic method was not specified in one of the included

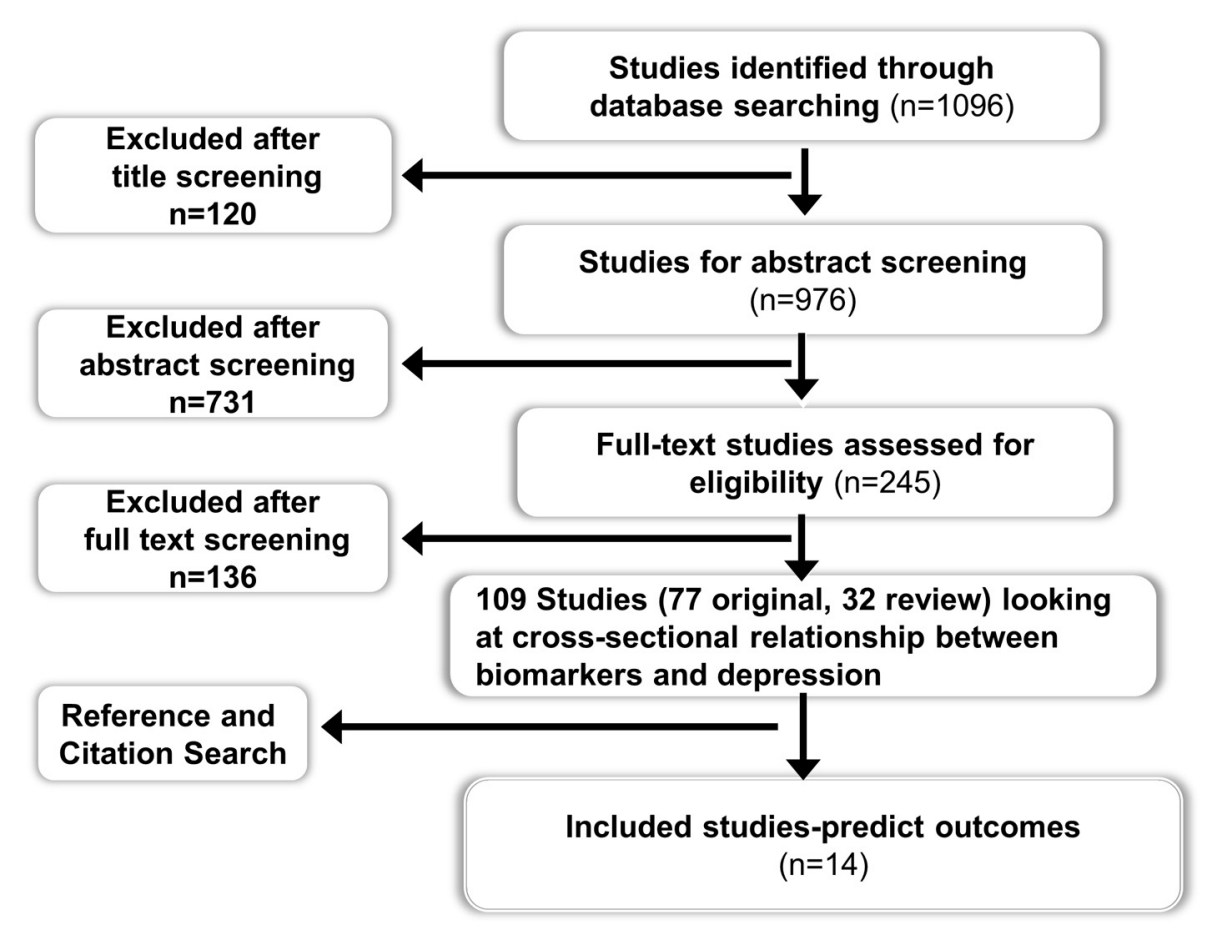

FIGURE 1 | Flow chart for the systematic review on the role of peripheral biomarkers predicting outcomes in patients with depression. 


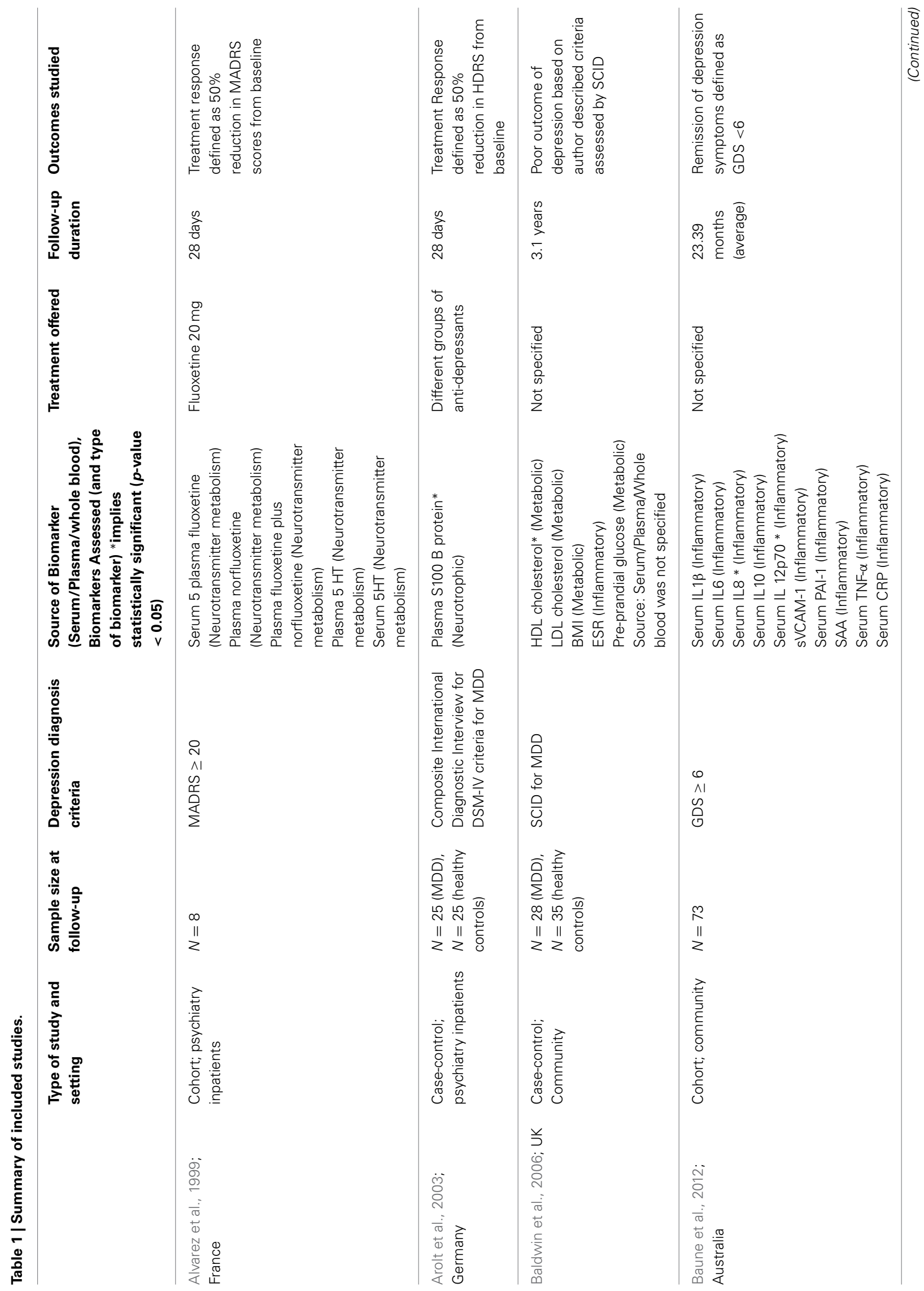




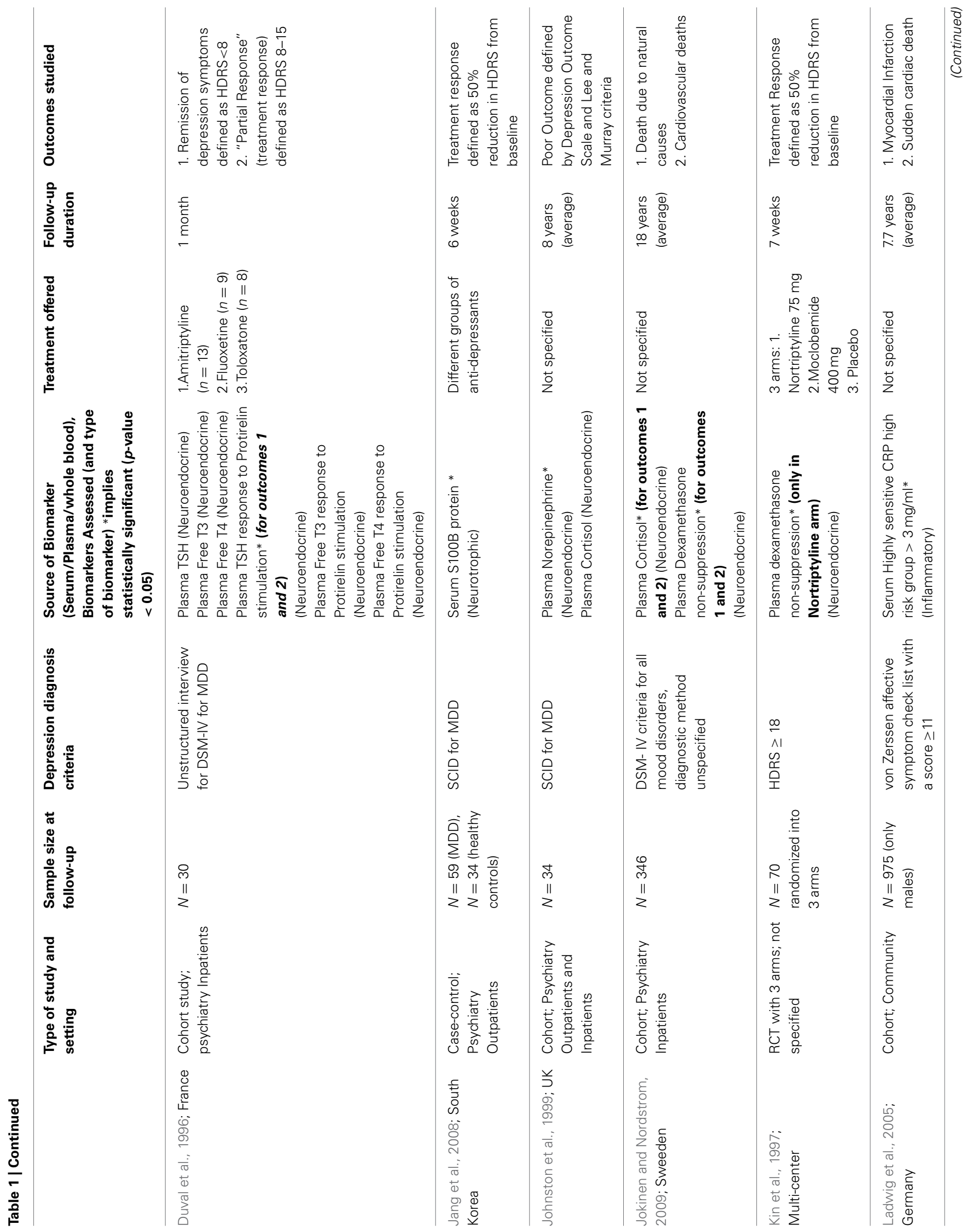




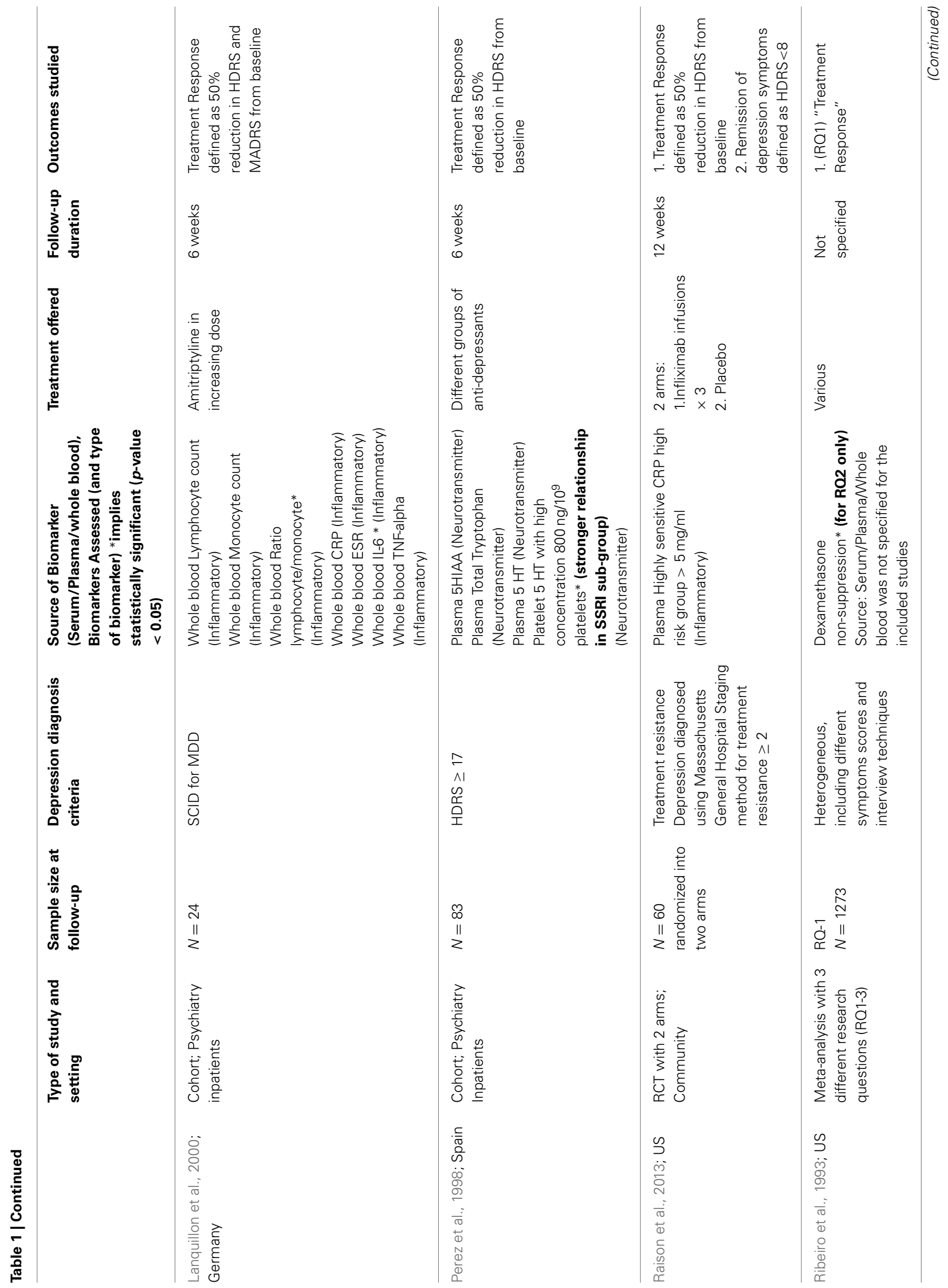


studies (Jokinen and Nordstrom, 2009). The nature of the treatment was specified in nine studies(Duval et al., 1996; Kin et al., 1997; Perez et al., 1998; Alvarez et al., 1999; Lanquillon et al., 2000; Arolt et al., 2003; Jang et al., 2008; Binder et al., 2009; Raison et al., 2013); the relationship between outcome and baseline depression severity was only taken into account in 5 studies (Duval et al., 1996; Johnston et al., 1999; Lanquillon et al., 2000; Arolt et al., 2003; Baldwin et al., 2006). The included meta-analysis had a variable sample size and follow-up duration depending on the different research questions considered by the study and the diagnostic methods used were heterogeneous including various symptoms scores and interview techniques (Ribeiro et al., 1993).

\section{BIOMARKERS STUDIED AND METHOD OF COLLECTION}

The included studies assessed 36 different peripheral biomarkers at baseline as a predictor of clinical outcomes. These biomarkers were measured in serum or plasma and could be broadly classified as pertaining to inflammatory $(n=14)$, neurotransmitter metabolism $(n=9)$, neuroendocrine $(n=8)$, metabolic $(n=4)$, and neurotrophic $(n=1)$ systems. All included studies assessed statistical significance based on the criteria of having a $p$-value less than 0.05 . Twelve biomarkers were found to be statistically significant in predicting outcomes (summarized in Figure 2). Inflammatory (Lanquillon et al., 2000; Ladwig et al., 2005; Baldwin et al., 2006; Baune et al., 2012; Raison et al., 2013) and neuroendocrine (Ribeiro et al., 1993; Duval et al., 1996; Kin et al., 1997; Johnston et al., 1999; Jokinen and Nordstrom, 2009) biomarkers were each assessed in five of the included studies, followed by neurotransmitter (Perez et al., 1998; Alvarez et al., 1999; Johnston et al., 1999) biomarkers in three studies, neurotrophic (Arolt et al., 2003; Jang et al., 2008) biomarker in two studies, while metabolic (Baldwin et al., 2006) biomarkers were assessed in only one study.

The source of peripheral biomarker measurement was plasma in half of the included studies $(n=7)$ (Duval et al., 1996; Kin et al., 1997; Perez et al., 1998; Johnston et al., 1999; Arolt et al., 2003; Jokinen and Nordstrom, 2009; Raison et al., 2013); serum in three studies (Ladwig et al., 2005; Jang et al., 2008; Baune et al., 2012); whole blood (Lanquillon et al., 2000) and mixed (both serum and plasma) (Alvarez et al., 1999) in 1 study each; and not reported in two of the included studies (Ribeiro et al., 1993; Baldwin et al., 2006). Four of the included studies did not describe the procedures of measuring peripheral biomarker in detail (Ribeiro et al., 1993; Duval et al., 1996; Baldwin et al., 2006; Jokinen and Nordstrom, 2009). Four of the included studies describe the anticoagulant used for collecting plasma samples with ethylenediaminetetraacetic acid (EDTA) used by two studies (Perez et al., 1998; Raison et al., 2013); and heparin (Arolt et al., 2003) and sodium citrate (Alvarez et al., 1999) used by one study each.

TYPES OF CLINICAL OUTCOMES STUDIED AND STATISTICAL METHODS The majority of included studies $(n=12)$ (Ribeiro et al., 1993; Duval et al., 1996; Kin et al., 1997; Perez et al., 1998; Alvarez et al., 1999; Johnston et al., 1999; Lanquillon et al., 2000; Arolt et al., 2003; Baldwin et al., 2006; Jang et al., 2008; Baune et al., 2012; 


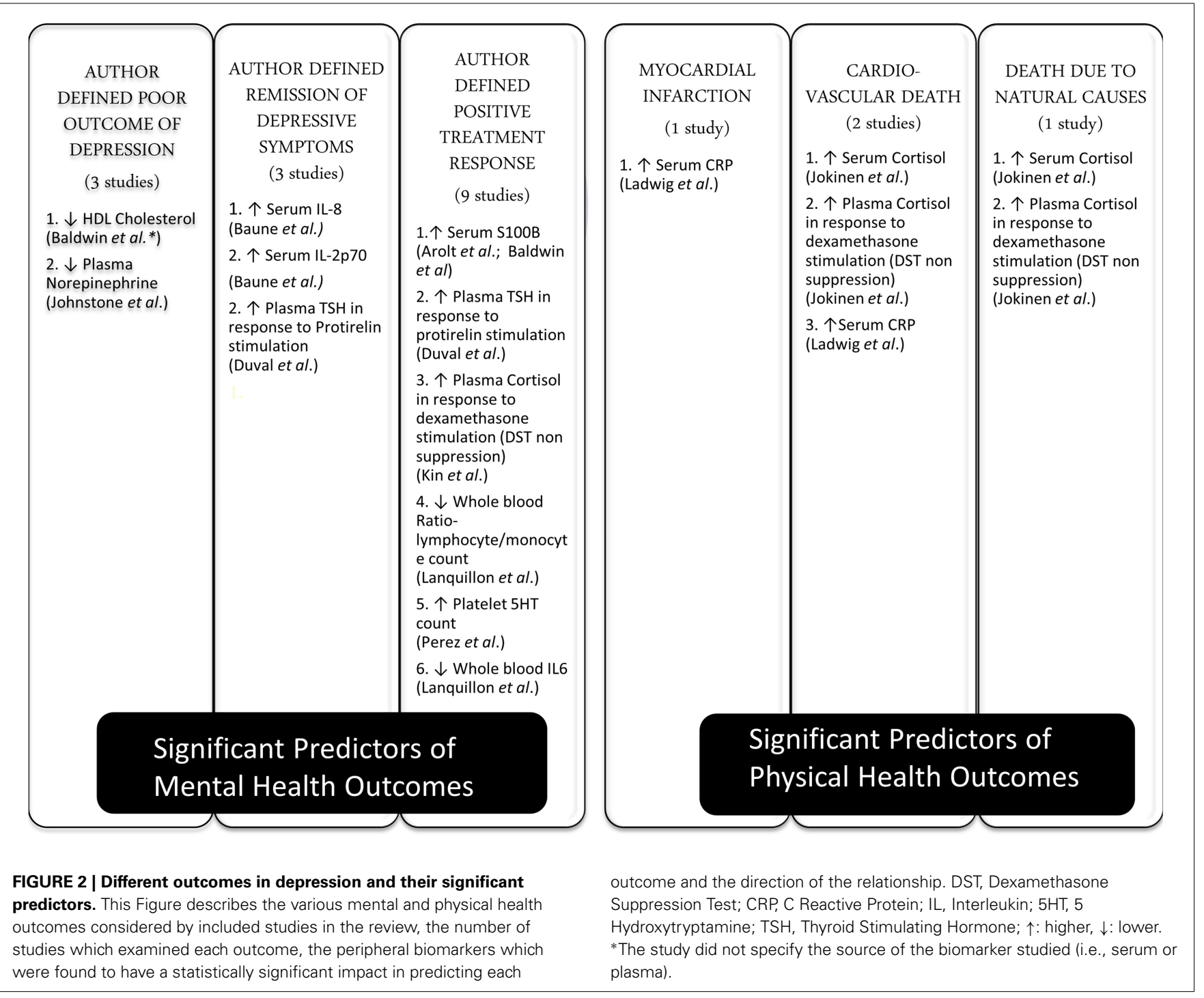

Raison et al., 2013) examined outcomes pertaining to mental health or depressive symptoms, with only two studies assessing physical health outcomes (Ladwig et al., 2005; Jokinen and Nordstrom, 2009). Author defined positive treatment response to anti-depressants with improvement in depressive symptoms [e.g., $50 \%$ reduction in depression rating scale Hamilton Depression Rating Scale (HDRS) from baseline] was the commonest outcome considered by nine included studies (Ribeiro et al., 1993; Duval et al., 1996; Kin et al., 1997; Perez et al., 1998; Alvarez et al., 1999; Lanquillon et al., 2000; Arolt et al., 2003; Jang et al., 2008; Raison et al., 2013). This was followed by other mental health outcomes such as author defined criteria for poor outcome of depressive symptoms $(n=3)$ (Ribeiro et al., 1993; Johnston et al., 1999; Baldwin et al., 2006) for e.g., Lee and Murray operational criteria for outcome in depression; and remission of depression symptoms $(n=3)$ (Duval et al., 1996; Baune et al., 2012; Raison et al., 2013) for e.g., HDRS $<8$ at follow-up. The physical health outcomes measured were cardiovascular deaths $(n=2)$ (Ladwig et al., 2005; Jokinen and Nordstrom, 2009), myocardial infarction $(n=1)$ (Ladwig et al., 2005) and death due to natural causes $(n=1)$ (Jokinen and Nordstrom, 2009). The usefulness of statistical models for physical outcomes was not compared against routinely used and evidence backed risk scores such as the Framingham score for cardiovascular events. Biomarkers were shown to be statistically significant in predicting all of the six outcomes considered, including mental and physical outcomes. Figure 2 summarizes the six different mental and physical health outcomes studied, the number of studies which examined each outcome, the 12 peripheral biomarkers which were noted to be statistically significant in predicting each outcome and the direction of the relationship between the biomarker and the outcome.

The Area Under Curve (AUC) statistic was presented only by 1 study, with AUC statistic for Dexamethasone suppression test (DST) reported as 0.65 for predicting increased incidence of cardiovascular deaths only for the male subset of their sample (Jokinen and Nordstrom, 2009). DST was found to have a significant impact in predicting three different outcomes in 
two different studies; which included adverse outcomes such as increased incidence of all-cause mortality and cardiovascular deaths (Jokinen and Nordstrom, 2009), and favorable outcome such as positive treatment response to anti-depressants (Kin et al., 1997). In the included meta-analysis, DST failed to have a significant impact in predicting positive response to anti-depressants but was significant in predicting positive response to placebo (Ribeiro et al., 1993). Elevated levels of serum S100B was the only biomarker which was found to have a statistically significant role in predicting the same clinical outcome (positive treatment response to anti-depressants) in more than one included studies (Arolt et al., 2003; Jang et al., 2008).

\section{PATIENT DEMOGRAPHICS AND ATTRITION RATE}

Description of patient demographics, co-morbid conditions and attrition at follow-up for included studies is provided in Table 2. Details of the age of participants were not described by three studies (Ribeiro et al., 1993; Kin et al., 1997; Baune et al., 2012); while information on gender distribution was missing from five studies (Ribeiro et al., 1993; Kin et al., 1997; Arolt et al., 2003; Baldwin et al., 2006; Baune et al., 2012). The socio-economic status of participants was very poorly described with only two studies (Ladwig et al., 2005; Raison et al., 2013) characterizing it and only one study (Ladwig et al., 2005) including socio-economic status in their statistical analysis. Patients with pre-existing chronic disease were excluded by the majority of the included studies $(n=8)$ (Duval et al., 1996; Perez et al., 1998; Johnston et al., 1999; Lanquillon et al., 2000; Arolt et al., 2003; Ladwig et al., 2005; Jang et al., 2008; Jokinen and Nordstrom, 2009) and chronic disease status was not considered or described by four of the included studies (Ribeiro et al., 1993; Kin et al., 1997; Alvarez et al., 1999; Baldwin et al., 2006). Of the two studies which included patients with co-existing chronic disease (Baune et al., 2012; Raison et al., 2013), only one study accounted for the number of co-morbidities in their statistical analysis (Raison et al., 2013). The reported participant attrition rate at follow-up varied from 0 to 44\%; with two included studies (Ribeiro et al., 1993; Baune et al., 2012) not specifying the details of attrition.

\section{DISCUSSION}

\section{SUMMARY OF FINDINGS}

Our review shows that blood based peripheral biomarkers were statistically significant in predicting six different clinical outcomes in participants with depression. Outcomes related to both mental health (depressive symptoms) and physical health were statistically associated with pre-treatment levels of peripheral biomarkers; however only two studies investigated outcomes related to physical health. Twelve different biomarkers related to five different biological systems (inflammatory, neuroendocrine, neurotransmitter metabolism, neurotrophic, and metabolic) were found to have a potential role in predicting outcomes of depression. Despite extensive research on the biomarkers of etiopathogenesis of depression, there is limited published research exploring its translational application in clinical practice. Furthermore, the research is of generally limited quality and lacks clinical utility.
The included studies have several methodological problems. The study sample size was small and follow-up duration was short in the majority of included studies. The majority of included studies used questionnaire scores using symptom count for diagnosing depression at baseline, while the gold standard interview technique for depression diagnosis was used only by a minority. Baseline severity of depressive symptoms assessed using symptom count is associated with higher rate of relapse in patients with depression (Ishak et al., 2013) but accounting for the baseline severity of depressive symptoms was only undertaken by a minority of studies. There is a strong evidence base suggesting that depression is two to three time more prevalent in patients with co-existing chronic disease as compared to the general population (Egede, 2007; Moussavi et al., 2007; Mitchell et al., 2013) but the effect of co-morbidity on clinical outcomes was examined by only two studies.

Importantly, the clinical implications of the observed statistical relationships in the included studies were not well explained. The c-statistic or area under receiver operating characteristic (ROC) curve (Cook, 2007), which is regarded as one of the standard methods for evaluating clinical discriminating power of a statistical model, was reported by only one study. The usefulness of statistical models for physical outcomes in the included study was not compared against robustly validated and routinely used risk scores such as the Framingham score for cardiovascular events (D'Agostino et al., 2008). Finally, some of the biomarkers included in this review are complicated to measure and likely to be expensive. The source and method of measurement for biomarkers in the included studies were heterogeneous and this may have an influence on assay levels of the biomarkers measured (Tort et al., 2003; Wong et al., 2008; Yu et al., 2011). The cost implications of doing these tests were not considered in detail in the included studies and this is likely to be a relevant factor when considering their potential use in routine clinical practice. There is some evidence that peripheral biomarkers may have a role in stratifying depression severity by means of predicting various physical and mental health outcomes in depression but further more robust research needs to be done in this area to address the shortcomings of the available evidence.

\section{OUTCOMES BASED APPROACH IN DEPRESSION SEVERITY STRATIFICATION}

The use of prediction rules and biomarkers to inform clinical decision making is not a novel concept. It has been used in making management decisions in a wide variety of clinical scenarios such as patients presenting with high cholesterol, atrial fibrillation, chest pain, ankle injury, and intensive care (Reilly and Evans, 2006). In psychiatry, it has been proposed to use this principle for predicting inpatient violence (Abderhalden et al., 2006). Depression contributes to disease burden not only owing to reduction in quality of life and functional productivity, but also due to the increased risk of adverse physical outcomes such as hospitalization and mortality (Ferrari et al., 2013). There is strong evidence showing an association of depression (MDD and mild depression) with increased risk of adverse physical outcomes such as all-cause mortality, cardiovascular disease, hypertension, stroke, diabetes, alzeimer's disease, obesity, and cancer 
Table 2 | Patient population and attrition rates in included studies.

\begin{tabular}{|c|c|c|c|c|}
\hline Study & $\begin{array}{l}\text { Mean Age in years (Standard } \\
\text { Deviation, if available) and Sex } \\
\text { F, Females; M, Males }\end{array}$ & Socio-economic status & Co-morbid medical conditions & $\begin{array}{l}\text { Participant numbers } \\
\text { Number of participants } \\
\text { at baseline (B) and } \\
\text { follow-up(FU); attrition } \\
\text { in percentage }\end{array}$ \\
\hline Alvarez et al., 1999 & $\begin{array}{l}45(13.8) \\
6 \mathrm{~F}, 2 \mathrm{M}\end{array}$ & Not described & Not described & $\begin{array}{l}10 \mathrm{~B} \\
8 \mathrm{FU} 20 \% \text { attrition }\end{array}$ \\
\hline Arolt et al., 2003 & $\begin{array}{l}46.4 \text { (9.8) } \\
\text { Not described }\end{array}$ & Not described & $\begin{array}{l}\text { Patients with co-morbid } \\
\text { conditions excluded from study }\end{array}$ & $\begin{array}{l}25 \text { B } \\
25 \text { FU No attrition }\end{array}$ \\
\hline Baldwin et al., 2006 & $\begin{array}{l}73.9 \\
\text { Not described }\end{array}$ & Not described & Not described & $\begin{array}{l}50 \mathrm{~B} \\
28 \mathrm{FU} 44 \% \text { attrition }\end{array}$ \\
\hline Baune et al., 2012 & Not described & Not described & $\begin{array}{l}\text { Presence/absence of a list of } \\
\text { medical conditions noted and } \\
\text { entered into statistical analysis }\end{array}$ & $\begin{array}{l}73 \text { B } \\
\text { Sample size at follow-up } \\
\text { not specified }\end{array}$ \\
\hline Duval et al., 1996 & $\begin{array}{l}39.8(12.9) ; \\
19 \mathrm{M}, 11 \mathrm{~F}\end{array}$ & Not described & $\begin{array}{l}\text { Patients with co-morbid } \\
\text { conditions excluded from study }\end{array}$ & $\begin{array}{l}30 \mathrm{~B} \\
30 \mathrm{FU} \text { No attrition }\end{array}$ \\
\hline Jang et al., 2008 & $\begin{array}{l}60.3 ; \\
43 F, 16 M\end{array}$ & Not described & $\begin{array}{l}\text { Patients with co-morbid } \\
\text { conditions excluded from study }\end{array}$ & $\begin{array}{l}59 \text { B } \\
59 \text { FU No attrition }\end{array}$ \\
\hline Johnston et al., 1999 & $\begin{array}{l}47 ; \\
24 F, 10 M\end{array}$ & Not described & $\begin{array}{l}\text { Patients with co-morbid } \\
\text { conditions excluded from study }\end{array}$ & $\begin{array}{l}47 \text { B } \\
34 \text { FU 27.6\% attrition }\end{array}$ \\
\hline $\begin{array}{l}\text { Jokinen and } \\
\text { Nordstrom, } 2009\end{array}$ & $\begin{array}{l}52(16.4) \\
256 \mathrm{~F}, 126 \mathrm{M}\end{array}$ & Not described & $\begin{array}{l}\text { Patients with co-morbid } \\
\text { conditions excluded from study }\end{array}$ & $\begin{array}{l}382 \text { B } \\
346 \text { FU } 9.4 \% \text { attrition }\end{array}$ \\
\hline Kin et al., 1997 & Not described & Not described & Not described & $\begin{array}{l}95 \text { B } \\
70 \text { FU } 26.3 \% \text { attrition }\end{array}$ \\
\hline Ladwig et al., 2005 & $\begin{array}{l}57.75(7.8) \\
975 \mathrm{M}\end{array}$ & $\begin{array}{l}\text { Education status } \\
\text { described and entered } \\
\text { into statistical analysis }\end{array}$ & $\begin{array}{l}\text { Patients with co-morbid } \\
\text { conditions excluded from study }\end{array}$ & $\begin{array}{l}986 \text { B } \\
975 \text { FU } 1.1 \% \text { attrition }\end{array}$ \\
\hline $\begin{array}{l}\text { Lanquillon et al., } \\
2000\end{array}$ & $\begin{array}{l}53.5 \\
15 F, 9 M\end{array}$ & Not described & $\begin{array}{l}\text { Patients with co-morbid } \\
\text { conditions excluded from study }\end{array}$ & $\begin{array}{l}35 \text { B } \\
24 \text { FU 30.5\% attrition }\end{array}$ \\
\hline Perez et al., 1998 & $\begin{array}{l}\text { M } 45(2.9), \text { F } 44.9(2.0) \\
59 F, 24 M\end{array}$ & Not described & $\begin{array}{l}\text { Patients with co-morbid } \\
\text { conditions excluded from study }\end{array}$ & $\begin{array}{l}89 \text { B } \\
83 \text { FU } 6.7 \% \text { attrition }\end{array}$ \\
\hline Raison et al., 2013 & $\begin{array}{l}\text { 42.5(8.2) placebo group, } 44.3 \\
\text { (9.4) intervention group; } \\
40 \mathrm{~F}, 20 \mathrm{M}\end{array}$ & $\begin{array}{l}\text { Education and } \\
\text { employment status } \\
\text { described but not } \\
\text { entered into statistical } \\
\text { analysis }\end{array}$ & $\begin{array}{l}\text { Notable exclusions- previous } \\
\text { history of cancer, history of } \\
\text { unstable cardiovascular, } \\
\text { endocrinologic, hematologic, } \\
\text { hepatic, renal, or neurologic } \\
\text { disease (determined by } \\
\text { Physical examination and } \\
\text { laboratory testing). } \\
\text { Number of co-morbid medical } \\
\text { conditions noted and entered into } \\
\text { statistical analysis }\end{array}$ & $\begin{array}{l}60 \mathrm{~B} \\
60 \mathrm{FU} \text { No attrition }\end{array}$ \\
\hline Ribeiro et al., 1993 & Not described & Not described & Not described & Not described \\
\hline
\end{tabular}

(Penninx et al., 2013). Physical adverse outcomes associated with depression attribute to a significant amount of morbidity and mortality (Ferrari et al., 2013; Penninx et al., 2013). Consequently, it is imperative that the risk of adverse physical outcomes associated with depression should be considered while taking decisions regarding depression severity stratification and subsequent management. Crucially, the clinical utility of biomarkers in predicting physical outcomes in depression, if any, should be 
compared and validated against some of the established and available risk scoring systems (e.g., Framingham, D’Agostino et al., 2008) for physical outcomes.

\section{ROLE OF PERIPHERAL BIOMARKERS IN IDENTIFYING DEPRESSION SUBTYPES}

The use of peripheral biomarkers in identifying different subtypes of depression has been explored by other studies in the literature. A meta-analysis reviewing the association between HPA axis hyperactivity (Dexamethasone non-suppression) and depression suggested a dose-response relationship, with patients with mild depression showing higher HPA hyperactivity compared to controls but lower than that of patients with MDD (Stetler and Miller, 2011). Peripheral inflammatory markers such as Tumor necrotic factor (TNF)- $\alpha$ and IL (Interleukin)-6, serum neopterin have been shown to have association with melancholic subtypes of MDD (Maes et al., 2012; Dunjic-Kostic et al., 2013). A review of metabolic and neuroendocrine biomarkers (Body mass index BMI, waist-hip ratio, fasting glucose, serum adrenocorticotropic hormone ACTH) in pre-menopausal women with MDD supported their role in identifying three different subtypes of MDDmelancholic, atypical and undifferentiated (Cizza et al., 2012). This suggests that peripheral biomarkers may have a useful role in addressing some of the challenges posed by heterogeneity of depression, with a particular biomarker likely to have a more useful role in a specific subtype of depression. However, before any decisions are made, much better high quality research is needed.

\section{NOVEL BIOMARKERS IN DEPRESSION}

In recent years, novel techniques in proteomics, metabolomics, genetics, and epigenetics have led to several new biomarkers being proposed in depression. Proteomic techniques have been used to identify nine differentiating proteins belonging to lipid metabolism and immune system from treatment naïve patients with depression, when compared against healthy controls (Xu et al., 2012). Similarly, metabolomic techniques such as nuclear magnetic response (NMR) based analysis of both urine and plasma have been utilized to identify differentiating proteins related to lipid metabolism and neurotransmitter system with good accuracy in treatment naïve patients with depression, when compared to healthy controls (Zheng et al., 2012a,b). The role of brain-derived neurotrophic gene polymorphisms, glucocorticoid receptor polymorphism and serotonin gene receptor have been studied in diagnosis and prognostification of depression with some encouraging results (Chi et al., 2010; Szczepankiewicz et al., 2011; Uher et al., 2011). Although the findings from genome wide association studies (GWAS) till date in depression have failed to make a major breakthrough, they may have a potential role in stratification of depression and further research is ongoing (Wray et al., 2012; Flint and Kendler, 2014). Thus, these emerging techniques and biomarkers may have a role in diagnosis, identifying specific subtypes of depression and prognostification in depression (Schneider and Prvulovic, 2013).

\section{MULTIPLE BIOMARKERS, ALLOSTATIC LOAD, AND DEPRESSION}

The term allostasis refers to the adaptive physiological responses organisms activate when homeostasis is disrupted during acute stress, real or interpreted threats (McEwen and Stellar, 1993). When chronically activated, allostatic mechanisms become physiologically taxing — or an allostatic load (AL) — that consequently increase one's susceptibility to disease (McEwen, 1998). There is some early evidence to suggest that an index comprising multiple biomarkers or AI may exhibit a stronger relationship with depressive symptoms, especially in elderly populations, when compared with examination of individual biomarkers in isolation (Juster et al., 2011). The role of multiple biomarkers in risk assessment and predicting outcomes in patients with depression needs to be explored and compared against the role of individual biomarkers.

\section{LIMITATIONS}

Our search strategy was limited to studies published in English language. A variety of other biomarkers such as genetic, imaging and CSF biomarkers may have a role in depression stratification by predicting clinical outcomes (Schneider and Prvulovic, 2013). However, this review considered only peripheral or bloodbased biomarkers used in current clinical practice due to their comparative non-invasive nature and ease of measurement. The uncertainty surrounding management decisions in patients with depression in current practice is a particular issue at the time of initial presentation (Davidson, 2010). Hence, this review was focussed on addressing the issue of the use of peripheral biomarkers at baseline or pre-treatment as a predictive tool of clinical outcome (both mental and physical) and not on assessing changes in a peripheral biomarker level following treatment for depression.

\section{FUTURE RESEARCH}

There is a need for further research in this area, involving large scale studies with longer duration of follow-up, better characterization of patient populations and inclusion of patients with chronic diseases. An "ideal” scientific process for a biomarker evaluation in clinical risk discrimination has been highlighted in other fields such as cardiovascular disease, a similar approach can be adopted for biomarkers of depression (Welsh et al., 2008). Further epidemiological studies of greater quality which minimize potential bias and evaluate clinical utility are urgently needed. Future studies also need to incorporate other physical health outcomes such as rate of cardiovascular events, incidence of cancer and all-cause mortality associated with depression and compare validity against established benchmarks, along with mental health outcomes related to depression symptoms.

\section{CONCLUSION}

Pre-treatment levels of 12 different blood based peripheral biomarkers related to five different biological pathways were found to have a statistically significant relationship with outcomes in patients with depression. Six different outcomes in depression were predicted using these biomarkers, pertaining to both physical and mental health, but the clinical implications remain unclear. It appears likely that peripheral biomarkers may have an important role in helping clinicians to stratify depression severity and to predict clinical outcomes. However, the available evidence has multiple methodological limitations which must be overcome to make any real clinical headway; in particular, interaction between these biomarkers, depressive symptoms and co-morbid physical conditions needs to be explored further. 


\section{AUTHOR CONTRIBUTIONS}

Literature search was carried out by Bhautesh D. Jani and Barbara I. Nicholl. Title, abstract and full text screening followed by reference and citation searching and data extraction were carried out by Bhautesh D. Jani and Gary McLean. All authors contributed to the manuscript.

\section{ACKNOWLEDGMENTS}

The study was funded by Chief Scientist Office, Scotland $\mathrm{CAF} / 12 / 04$. The funders had no role in study design, data collection and analysis, decision to publish, or preparation of the manuscript.

\section{REFERENCES}

Abderhalden, C., Needham, I., Dassen, T., Halfens, R., Haug, H. J., and Fischer, J. (2006). Predicting inpatient violence using an extended version of the BrosetViolence-Checklist: instrument development and clinical application. BMC Psychiatry 6:17. doi: 10.1186/1471-244X-6-17

Alvarez, J.-C., Gluck, N., Fallet, A., Gregoire, A., Chevalier, J.-F., Advenier, C., et al. (1999). Plasma serotonin level after 1 day of fluoxetine treatment: a biological predictor for antidepressant response? Psychopharmacology (Berl.) 143, 1999. doi: 10.1007/s002130050924

American Psychiatric Association. (2000). Diagnostic and Statistical Manual of Mental Disorders (DSM-IV-TR). Washington, DC: American Psychiatric Association.

American Psychiatric Association. (2013). Diagnostic and Statistical Manual of Mental Disorders (DSM-V). Washington, DC: American Psychiatric Association.

Arolt, V., Peters, M., Erfurth, A., Wiesmann, M., Missler, U., Rudolf, S., et al. (2003). S100B and response to treatment in major depression: a pilot study. Eur. Neuropsychopharmacol. 13, 235-239. doi: 10.1016/S0924-977X(03)00016-6

Baldwin, R. C., Gallagley, A., Gourlay, M., Jackson, A., and Burns, A. (2006). Prognosis of late life depression: a three-year cohort study of outcome and potential predictors. Int. J. Geriatr. Psychiatry 21, 57-63. doi: 10.1002/gps.1424

Baune, B. T., Smith, E., Reppermund, S., Air, T., Samaras, K., Lux, O., et al. (2012). Inflammatory biomarkers predict depressive, but not anxiety symptoms during aging: the prospective Sydney memory and aging study. Psychoneuroendocrinology 37, 1521-1530. doi: 10.1016/j.psyneuen.2012.02.006

Binder, E. B., Kunzel, H. E., Nickel, T., Kern, N., Pfennig, A., Majer, M., et al. (2009). HPA-axis regulation at in-patient admission is associated with antidepressant therapy outcome in male but not in female depressed patients. Psychoneuroendocrinology 34, 99-109. doi: 10.1016/j.psyneuen.2008.08.018

Biomarkers Definitions Working Group. (2001). Biomarkers and surrogate endpoints: preferred definitions and conceptual framework. Clin. Pharmacol. Ther. 69, 89-95. doi: 10.1067/mcp.2001.113989

Carroll, B. J., Feinberg, M., Greden, J. F., Tarika, J., Albala, A. A., Haskett, R. F, et al. (1981). A specific laboratory test for the diagnosis of melancholia. Standardization, validation, and clinical utility. Arch. Gen. Psychiatry 38, 15-22. doi: 10.1001/archpsyc.1981.01780260017001

Chi, M. H., Chang, H. H., Lee, S.-Y., Lee, I. H., Gean, P. W., Yang, Y. K., et al. (2010). Brain derived neurotrophic factor gene polymorphism (Val66Met) and shortterm antidepressant response in major depressive disorder. J. Affect. Disord. 126, 430-435. doi: 10.1016/j.jad.2010.07.006

Cizza, G., Ronsaville, D. S., Kleitz, H., Eskandari, F., Mistry, S., Torvik, S., et al. (2012). Clinical subtypes of depression are associated with specific metabolic parameters and circadian endocrine profiles in women: the power study. PLoS ONE 7:e28912. doi: 10.1371/journal.pone.0028912

Cook, N. R. (2007). Use and misuse of the receiver operating characteristic curve in risk prediction. Circulation 115, 928-935. doi: 10.1161/CIRCULATIONAHA.106.672402

Coppen, A., Eccleston, E. G., and Peet, M. (1973). Total and free tryptophan concentration in the plasma of depressive patients. Lancet 2, 60-63. doi: 10.1016/S0140-6736(73)93259-5

Cuijpers, P., and Smit, F. (2002). Excess mortality in depression: a meta-analysis of community studies. J. Affect. Disord. 72, 227-236. doi: 10.1016/S01650327(01)00413-X
Cuijpers, P., Smit, F., and van Straten, A. (2007). Psychological treatments of subthreshold depression: a meta-analytic review. Acta Psychiatr. Scand. 115, 434-441. doi: 10.1111/j.1600-0447.2007.00998.x

D’Agostino, R. B. Sr., Vasan, R. S., Pencina, M. J., Wolf, P. A., Cobain, M., Massaro, J. M., et al. (2008). General cardiovascular risk profile for use in primary care: the Framingham Heart Study. Circulation 117, 743-753.

Davidson, J. R. (2010). Major depressive disorder treatment guidelines in America and Europe. J. Clin. Psychiatry 71(Suppl. E1), e04. doi: 10.4088/JCP.9058se1c.04gry

Dunjic-Kostic, B., Ivkovic, M., Radonjic, N. V., Petronijevic, N. D., Pantovic, M., Damjanovic, A., et al. (2013). Melancholic and atypical major depression-connection between cytokines, psychopathology and treatment. Prog. Neuropsychopharmacol. Biol. Psychiatry 43, 1-6. doi: 10.1016/j.pnpbp.2012.11.009

Duval, F., Mokrani, M. C., Crocq, M. A., Jautz, M., Bailey, P., Diep, T. S., et al. (1996). Effect of antidepressant medication on morning and evening thyroid function tests during a major depressive episode. Arch. Gen. Psychiatry 53, 833-840. doi: 10.1001/archpsyc.1996.01830090081012

Egede, L. E. (2007). Major depression in individuals with chronic medical disorders: prevalence, correlates and association with health resource utilization, lost productivity and functional disability. Gen. Hosp. Psychiatry 29, 409-416. doi: 10.1016/j.genhosppsych.2007.06.002

Ferrari, A. J., Charlson, F. J., Norman, R. E., Patten, S. B., Freedman, G., Murray, C. J. L., et al. (2013). Burden of depressive disorders by country, sex, age, and year: findings from the global burden of disease study 2010. PLoS Med. 10:e1001547. doi: 10.1371/journal.pmed.1001547

Fisar, Z., and Raboch, J. (2008). Depression, antidepressants, and peripheral blood components. Neuro Endocrinol. Lett. 29, 17-28.

Flint, J., and Kendler, K. S. (2014). The genetics of major depression. Neuron 81, 484-503. doi: 10.1016/j.neuron.2014.01.027

Fountoulakis, K. N., Veroniki, A. A., Siamouli, M., and Moller, H. J. (2013). No role for initial severity on the efficacy of antidepressants: results of a multi-metaanalysis. Ann. Gen. Psychiatry 12:26. doi: 10.1186/1744-859X-12-26

Fournier, J. C., DeRubeis, R. J., Hollon, S. D., Dimidjian, S., Amsterdam, J. D., Shelton, R. C., et al. (2010). Antidepressant drug effects and depression severity: a patient-level meta-analysis. JAMA 303, 47-53. doi: 10.1001/jama.2009.1943

Gibbons, R. D., Hur, K., Brown, C. H., Davis, J. M., and Mann, J. J. (2012). Benefits from antidepressants: synthesis of 6-week patient-level outcomes from doubleblind placebo-controlled randomized trials of fluoxetine and venlafaxine. Arch. Gen. Psychiatry 69, 572-579. doi: 10.1001/archgenpsychiatry.2011.2044

Goldberg, D. (2011). The heterogeneity of major depression. World Psychiatry 10, 226-228.

Hegerl, U., Allgaier, A. K., Henkel, V., and Mergl, R. (2012). Can effects of antidepressants in patients with mild depression be considered as clinically significant? J. Affect. Disord. 138, 183-191. doi: 10.1016/j.jad.2011.05.015

Ishak, W. W., Greenberg, J. M., and Cohen, R. M. (2013). Predicting relapse in major depressive disorder using patient-reported outcomes of depressive symptom severity, functioning, and quality of life in the individual burden of illness index for depression (IBI-D). J. Affect. Disord. 151, 59-65. doi: 10.1016/j.jad.2013.05.048

Jang, B. S., Kim, H., Lim, S. W., Jang, K. W., and Kim, D. K. (2008). Serum S100B Levels and major depressive disorder: its characteristics and role in antidepressant response. Psychiatry Investig. 5, 193-198. doi: 10.4306/pi.2008.5.3.193

Johnston, T. G., Kelly, C. B., Stevenson, M. R., and Cooper, S. J. (1999). Plasma norepinephrine and prediction of outcome in major depressive disorder. Biol. Psychiatry 46, 1. doi: 10.1016/S0006-3223(99)00134-1

Jokinen, J., and Nordstrom, P. (2009). HPA axis hyperactivity and cardiovascular mortality in mood disorder inpatients. J. Affect. Disord. 116, 88-92. doi 10.1016/j.jad.2008.10.025

Juster, R. P., Marin, M. F., Sindi, S., Nair, N. P., Ng, Y. K., Pruessner, J. C., et al. (2011). Allostatic load associations to acute, 3-year and 6-year prospective depressive symptoms in healthy older adults. Physiol. Behav. 104, 360-364. doi: 10.1016/j.physbeh.2011.02.027

Khan, A., Leventhal, R. M., Khan, S. R., and Brown, W. A. (2002). Severity of depression and response to antidepressants and placebo: an analysis of the food and drug administration database. J. Clin. Psychopharmacol. 22, 40-45. doi: 10.1097/00004714-200202000-00007

Kin, N. M., Nair, N. P., Amin, M., Schwartz, G., Ahmed, S. K., Holm, P., et al. (1997). The dexamethasone suppression test and treatment outcome in 
elderly depressed patients participating in a placebo-controlled multicenter trial involving moclobemide and nortriptyline. Biol. Psychiatry 42, 925-931. doi: 10.1016/S0006-3223(97)00158-3

Kirsch, I., Deacon, B. J., Huedo-Medina, T. B., Scoboria, A., Moore, T. J., and Johnson, B. T. (2008). Initial severity and antidepressant benefits: a metaanalysis of data submitted to the Food and Drug Administration. PLoS Med 5:e45. doi: 10.1371/journal.pmed.0050045

Ladwig, K. H., Marten-Mittag, B., Lowel, H., Doring, A., and Koenig, W. (2005). Creactive protein, depressed mood, and the prediction of coronary heart disease in initially healthy men: results from the MONICA-KORA Augsburg Cohort Study 1984-1998. Eur. Heart J. 26, 2537-2542. doi: 10.1093/eurheartj/ehi456

Lanquillon, S., Krieg, J. C., Bening-Abu-Shach, U., and Vedder, H. (2000). Cytokine production and treatment response in major depressive disorder. Neuropsychopharmacology 22, 370-379. doi: 10.1016/S0893-133X(99)00134-7

Leuchter, A. F., Cook, I. A., Hamilton, S. P., Narr, K. L., Toga, A., Hunter, A. M., et al. (2010). Biomarkers to predict antidepressant response. Curr. Psychiatry Rep. 12, 553-562. doi: 10.1007/s11920-010-0160-4

Lopresti, A. L., Maker, G. L., Hood, S. D., and Drummond, P. D. (2014). A review of peripheral biomarkers in major depression: the potential of inflammatory and oxidative stress biomarkers. Prog. Neuropsychopharmacol. Biol. Psychiatry 48, 102-111. doi: 10.1016/j.pnpbp.2013.09.017

Lyness, J. M., Heo, M., Datto, C. J., Ten Have, T. R., Katz, I. R., Drayer, R., et al. (2006). Outcomes of minor and subsyndromal depression among elderly patients in primary care settings. Ann. Intern. Med. 144, 496-504. doi: 10.7326/0003-4819-144-7-200604040-00008

Macaluso, M., Drevets, W. C., and Preskorn, S. H. (2012). How biomarkers will change psychiatry. Part II: biomarker selection and potential inflammatory markers of depression. J. Psychiatr. Pract. 18, 281-286. doi: 10.1097/01.pra.0000416018.83709.3e

Maes, M. (2008). The cytokine hypothesis of depression: inflammation, oxidative \& nitrosative stress (IO\&NS) and leaky gut as new targets for adjunctive treatments in depression. Neuro Endocrinol. Lett. 29, 287-91.

Maes, M., Bosmans, E., Suy, E., Vandervorst, C., DeJonckheere, C., and Raus, J. (1991). Depression-related disturbances in mitogen-induced lymphocyte responses and interleukin-1 beta and soluble interleukin-2 receptor production. Acta Psychiatr. Scand. 84, 379-386. doi: 10.1111/j.1600-0447.1991.tb03163.x

Maes, M., Mihaylova, I., Kubera, M., and Ringel, K. (2012). Activation of cellmediated immunity in depression: association with inflammation, melancholia, clinical staging and the fatigue and somatic symptom cluster of depression. Prog. Neuropsychopharmacol. Biol. Psychiatry 36, 169-175. doi: 10.1016/j.pnpbp.2011.09.006

McEwen, B. S. (1998). Stress, adaptation, and disease. Allostasis and allostatic load. Ann. N. Y. Acad. Sci. 840, 33-44. doi: 10.1111/j.1749-6632.1998.tb09546.x

McEwen, B. S., and Stellar, E. (1993). Stress and the individual. Mechanisms leading to disease. Arch. Intern. Med. 153, 2093-101. doi: 10.1001/archinte.1993.00410180039004

McIntyre, R. S., Rasgon, N. L., Kemp, D. E., Nguyen, H. T., Law, C. W. Y., Taylor, V. H., et al. (2009). Metabolic syndrome and major depressive disorder: co-occurrence and pathophysiologic overlap. Curr. Diab. Rep. 9, 51-9. doi: 10.1007/s11892-009-0010-0

Mitchell, A. J., Ferguson, D. W., Gill, J., Paul, J., and Symonds, P. (2013). Depression and anxiety in long-term cancer survivors compared with spouses and healthy controls: a systematic review and meta-analysis. Lancet Oncol. 14, 721-732. doi: 10.1016/S1470-2045(13)70244-4

Mitchell, A. J., Vaze, A., and Rao, S. (2009). Clinical diagnosis of depression in primary care: a meta-analysis. Lancet 374, 609-619. doi: 10.1016/S01406736(09)60879-5

Moussavi, S., Chatterji, S., Verdes, E., Tandon, A., Patel, V., and Ustun, B. (2007). Depression, chronic diseases, and decrements in health: results from the World Health Surveys. Lancet 370, 851-858. doi: 10.1016/S0140-6736(07) 61415-9

Nemeroff, C. B. (2007). Prevalence and management of treatment-resistant depression. J. Clin. Psychiatry 68(Suppl. 8), 17-25.

Nierenberg, A. A., Rapaport, M. H., Schettler, P. J., Howland, R. H., Smith, J. A., Edwards, D., et al. (2010). Deficits in psychological well-being and qualityof-life in minor depression: implications for DSM-V. CNS Neurosci. Ther. 16, 208-216. doi: 10.1111/j.1755-5949.2009.00108.x

Penninx, B. W., Milaneschi, Y., Lamers, F., and Vogelzangs, N. (2013). Understanding the somatic consequences of depression: biological mechanisms and the role of depression symptom profile. BMC Med. 11:129. doi: 10.1186/1741-7015-11-129

Perez, V., Bel, N., Celada, P., Ortiz, J., Alvarez, E., and Artigas, F. (1998). Relationship between blood serotonergic variables, melancholic traits, and response to antidepressant treatments. J. Clin. Psychopharmacol. 18, 222-230. doi: 10.1097/00004714-199806000-00007

Raison, C. L., Rutherford, R. E., Woolwine, B. J., Shuo, C., Schettler, P., Drake, D. F., et al. (2013). A randomized controlled trial of the tumor necrosis factor antagonist infliximab for treatment-resistant depression: the role of baseline inflammatory biomarkers. JAMA Psychiatry 70, 31-41. doi: 10.1001/2013.jamapsychiatry. 4

Reilly, B. M., and Evans, A. T. (2006). Translating clinical research into clinical practice: impact of using prediction rules to make decisions. Ann. Intern. Med. 144, 201-209. doi: 10.7326/0003-4819-144-3-200602070-00009

Ribeiro, S. C., Tandon, R., Grunhaus, L., and Greden, J. F. (1993). The DST as a predictor of outcome in depression: a meta-analysis. Am. J. Psychiatry 150, 1618-1629. doi: 10.1176/ajp.150.11.1618

Rodriguez, M. R., Nuevo, R., Chatterji, S., and Ayuso-Mateos, J. L. (2012). Definitions and factors associated with subthreshold depressive conditions: a systematic review. BMC Psychiatry 12:181. doi: 10.1186/1471-244X-12-181

Sapolsky, R. M. (2004). Is impaired neurogenesis relevant to the affective symptoms of depression? Biol. Psychiatry 56, 137-139. doi: 10.1016/j.biopsych.2004.04.012

Schmidt, H. D., Shelton, R. C., and Duman, R. S. (2011). Functional biomarkers of depression: diagnosis, treatment, and pathophysiology. Neuropsychopharmacology 36, 2375-2394. doi: 10.1038/npp.2011.151

Schneider, B., and Prvulovic, D. (2013). Novel biomarkers in major depression. Curr. Opin. Psychiatry 26, 47-53. doi: 10.1097/YCO.0b013e32835a5947

Stetler, C., and Miller, G. E. (2011). Depression and hypothalamic-pituitaryadrenal activation: a quantitative summary of four decades of research. Psychosom. Med. 73, 114-126. doi: 10.1097/PSY.0b013e31820ad12b

Szczepankiewicz, A., Leszczynska-Rodziewicz, A., Pawlak, J., Rajewska-Rager, A., Dmitrzak-Weglarz, M., Wilkosc, M., et al. (2011). Glucocorticoid receptor polymorphism is associated with major depression and predominance of depression in the course of bipolar disorder. J. Affect. Disord. 134, 138-144. doi: 10.1016/j.jad.2011.06.020

Thase, M. E. (2006). Preventing relapse and recurrence of depression: a brief review of therapeutic options. CNS Spectr. 11, 12-21.

Tort, A. B. L., Dietrich, M. O., Goncalves, C. A., Souza, D. O., and Portela, L. V. C. (2003). Influence of anticoagulants on the measurement of S100B protein in blood. Clin. Biochem. 36, 629-632. doi: 10.1016/S0009-9120(03)00107-3

Uher, R., Caspi, A., Houts, R., Sugden, K., Williams, B., Poulton, R., et al. (2011). Serotonin transporter gene moderates childhood maltreatment's effects on persistent but not single-episode depression: replications and implications for resolving inconsistent results. J. Affect. Disord. 135, 56-65. doi: 10.1016/j.jad.2011.03.010

Uher, R., Tansey, K. E., Dew, T., Maier, W., Mors, O., Hauser, J., et al. (2014). An inflammatory biomarker as a differential predictor of outcome of depression treatment with escitalopram and nortriptyline. Am. J. Psychiatry 171, 1278-1286. doi: 10.1176/appi.ajp.2014.14010094

Vancampfort, D., Correll, C. U., Wampers, M., Sienaert, P., Mitchell, A. J., De Herdt, A., et al. (2013). Metabolic syndrome and metabolic abnormalities in patients with major depressive disorder: a meta-analysis of prevalences and moderating variables. Psychol. Med. 1-12. doi: 10.1017/S0033291713002778

Welsh, P., Packard, C. J., and Sattar, N. (2008). Novel antecedent plasma biomarkers of cardiovascular disease: improved evaluation methods and comparator benchmarks raise the bar. Curr. Opin. Lipidol. 19, 563-571. doi: 10.1097/MOL.0b013e32831551e0

WHO (2010). International Statistical Classification of Diseases and Related Health Problems (International Classification of Diseases) (ICD) 10th Revision - Version:2010. Available online at: http://apps.who.int/classifications/icd10/ browse/2010/en.

Wittchen, H. U., Hofler, M., and Meister, W. (2001). Prevalence and recognition of depressive syndromes in German primary care settings: poorly recognized and treated? Int. Clin. Psychopharmacol. 16, 121-135. doi: 10.1097/00004850200105000-00001

Wong, H.-L., Pfeiffer, R. M., Fears, T. R., Vermeulen, R., Ji, S., and Rabkin, C. S. (2008). Reproducibility and correlations of multiplex cytokine levels in asymptomatic persons. Cancer Epidemiol. Biomarkers Prev. 17, 3450-3456. doi: 10.1158/1055-9965.EPI-08-0311 
Wray, N. R., Pergadia, M. L., Blackwood, D. H. R., Penninx, B. W. J. H., Gordon, S. D., Nyholt, D. R., et al. (2012). Genome-wide association study of major depressive disorder: new results, meta-analysis, and lessons learned. Mol. Psychiatry 17, 36-48. doi: 10.1038/mp.2010.109

Xu, H.-B., Zhang, R.-F., Luo, D., Zhou, Y., Wang, Y., Fang, L., et al. (2012). Comparative proteomic analysis of plasma from major depressive patients: identification of proteins associated with lipid metabolism and immunoregulation. Int. J. Neuropsychopharmacol. 15, 1413-1425. doi: $10.1017 /$ S1461145712000302

Yu, Z., Kastenmuller, G., He, Y., Belcredi, P., Moller, G., Prehn, C., et al. (2011). Differences between human plasma and serum metabolite profiles. PLoS ONE 6:e21230. doi: 10.1371/journal.pone.0021230

Zheng, P., Gao, H. C., Li, Q., Shao, W. H., Zhang, M. L., Cheng, K., et al. (2012a). Plasma metabonomics as a novel diagnostic approach for major depressive disorder. J. Proteome Res. 11, 1741-1748. doi: 10.1021/pr2010082

Zheng, P., Wang, Y., Chen, L., Yang, D., Meng, H., Zhou, D., et al. (2012b). Identification and validation of urinary metabolite biomarkers for major depressive disorder. Mol. Cell Proteomics 12, 207-214. doi: 10.1074/mcp.M112.021816

Zunszain, P. A., Anacker, C., Cattaneo, A., Carvalho, L. A., and Pariante, C. M. (2011). Glucocorticoids, cytokines and brain abnormalities in depression. Prog. Neuropsychopharmacol. Biol. Psychiatry 35, 722-729. doi: 10.1016/j.pnpbp.2010.04.011

Conflict of Interest Statement: The authors declare that the research was conducted in the absence of any commercial or financial relationships that could be construed as a potential conflict of interest.

Received: 16 October 2014; accepted: 09 January 2015; published online: 02 February 2015.

Citation: Jani BD, McLean G, Nicholl BI, Barry SJE, Sattar N, Mair FS and Cavanagh $J$ (2015) Risk assessment and predicting outcomes in patients with depressive symptoms: a review of potential role of peripheral blood based biomarkers. Front. Hum. Neurosci. 9:18. doi: 10.3389/fnhum.2015.00018

This article was submitted to the journal Frontiers in Human Neuroscience. Copyright (c) 2015 Jani, McLean, Nicholl, Barry, Sattar, Mair and Cavanagh. This is an open-access article distributed under the terms of the Creative Commons Attribution License (CC BY). The use, distribution or reproduction in other forums is permitted, provided the original author(s) or licensor are credited and that the original publication in this journal is cited, in accordance with accepted academic practice. No use, distribution or reproduction is permitted which does not comply with these terms. 